\title{
Pugna entre lenguas romances e indigenismo en el español atlántico (1496-1600)
}

\author{
MARÍA-TERESA CÁCERES-LORENZO \\ Departamento de Filología Española, Clásica y Árabe, \\ Universidad de Las Palmas de Gran Canaria, Islas Canarias (España)
}

\begin{abstract}
Resumen
En la primera centuria de la historia del español atlántico se producen múltiples situaciones de contacto entre lenguas. Canarias es un episodio más en un proceso de incorporación léxica en la lengua española en el Nuevo Mundo. El análisis del vocabulario en los textos canarios proporciona claves del proceso de selección en una sociedad urbana en la que conviven principalmente españoles y portugueses (1496-1600). La pugna entre el español y la incorporación del indigenismo es una seña de identidad en la historia del español de ultramar. Canarias añade a este proceso el préstamo portugués que aparece en los textos cronísticos y oficiales junto a voces españolas e indígenas. El análisis cuantitativo y cualitativo permite conocer las claves del peso de cada aporte según los documentos.
\end{abstract}

\begin{abstract}
In the course of the first century of Atlantic Spanish, languages were in contact in many situations. The Canary Islands is one episode in the process of the lexical incorporation of the Spanish language in the New World. The analysis of the lexicon in Canary Islands texts provides us with key factors in the selection process in an urban society in which mainly Spanish and Portuguese populations lived together (1496-1600). The struggle between Spanish and the incorporation of indigenous words is an identity factor in the history of American Spanish. The Canary Islands add Portuguese loans to this process, as they appear in the chronicle and official texts together with Spanish and indigenous words. The quantitative and the qualitative analysis allow us to know the most significant keys to each contribution, depending on the documents.
\end{abstract}

En la colonización de las tierras de ultramar en los siglos XV y XVI, un cronista o escribano de lengua española podía encontrarse en la situación de tener que nombrar en los textos un objeto o ser vivo, una actividad o experiencia que no pertenecía a su marco de conocimiento. El proceso de dar nombre a la realidad ignota va acompañado de varios procedimientos lingüísticos. La dificultad de explicar lo que no se conoce se superaba con la incorporación de un préstamo

BHS 89.8 (2012) doi:10.3828/bhs.2012.60 
al español, con la creación léxica o con la transformación del vocabulario patrimonial, entre otras posibilidades. Las distintas situaciones socioculturales de contacto entre lenguas parecen haber influido en los procedimientos de la incorporación léxica en los documentos de esta centuria.

Tradicionalmente, a la hora de analizar el español atlántico desde la 1492 hasta finales del siglo XVI, se presentan datos de cómo el indigenismo se incorpora a la lengua española siguiendo distintas tendencias en dos contextos comunicativos distintos: Caribe (1492) y Nueva España (1521). Y queda con frecuencia olvidada los datos lingüísticos y extralingüísticos de lo que sucedió en Canarias (1496), considerada como el 'eslabón intermedio [...] y ese mundo, distinto Peninsular, próximo - sin embargo - al de la otra banda atlántica, y en el que los hombres y la naturaleza son una inaudita sorpresa' (Alvar 1996: 20).

Entre 1496 y 1600, en Canarias se conquista la última isla hasta los albores del siglo XVII, fecha en que decae la inmigración portuguesa. Dicho periodo posibilita la comprensión de cómo convivieron y 'lucharon' voces patrimoniales españolas, portuguesismos y los indigenismos guanches para aparecer en los documentos. El resultado del proceso de elección del vocabulario entre estas tres lenguas debe entenderse a la luz de datos históricos y culturales. Sin duda, son razones extralingüísticas las que guían el proceso de selección de una voz romance ibérica o de un indigenismo guanche.

Este proceso de incorporación de indigenismos a la lengua española se inicia en el Caribe, las voces antillanas se incorporan a través de los distintos textos (cronísticos, oficiales, cartas, etc.) en un porcentaje significativo desde el punto de vista cuantitativo. Los términos que provienen de la conquista antillana desde 1492 'se documentan profusamente, en una y otra obra, como palabras que habían obtenido ya plena carta de naturaleza en la lengua española' (Lope Blanch 1990: 167). En los documentos, los cronistas que iniciaron la empresa indiana hacen gala de conocer y usar en su vocabulario términos del Caribe como elementos que lo diferenciará de los que lleguen ulteriormente, que son considerados bisoños y poco expertos en la aventura americana (Zamora Munné 2002: 978).

Años más tarde, cuando la Corona de Castilla llegue a Tierra Firme (1521) estos mismos indigenismos del Caribe competirán con las voces nahuas a la hora de nombrar la nueva cultura que entra en contacto con el español. El resultado de esta pugna será la preferencia por los indigenismos del Caribe (salvo excepciones):

El náhuatl oponía sus propios términos, pero rara vez subsistieron: la lengua se había conformado en las Antillas para poder expresar esa nueva realidad que le nacía. Y allí, en las islas, se ventiló el destino americano del español. Muchos años de convivencia en la Nueva España abrirían los ojos a inéditas realidades, pero lo que se aprendió en Santo Domingo o en Cuba era ya español patrimonial cuando se conquista el continente; español - ya - tan verdadero como aquél que venía de Castilla la Vieja. (Alvar 1990: 35)

De una forma u otro, la lengua española sigue la tendencia de incorporar un gran número de indigenismos, y posteriormente, la pérdida paulatina en el que 
tan solo pervive la designación que el español necesita para nombrar al referente (véase Andión Herrero 2005, Bravo García y Cáceres 2011):

ha de producirse todavía, a partir de la experiencia acumulada en las circunstancias del diario vivir, al menos en bastantes casos; el proceso de selección que, por un lado elimine los indigenismos menos vinculados a las necesidades y percepciones cotidianas y, por otro, permita la penetración y la fijación de los vocablos autóctonos que cumplan dichas condiciones. Los textos cronísticos posteriores confirman, en buena medida, estas apreciaciones. (Enguita Utrilla 1994: 90)

Después de la novedad del primer contacto con los indígenas americanos del Caribe, los españoles conocen en el virreinato de la Nueva España otras grandes culturas prehispánicas, social y culturalmente desarrolladas que motivan una nueva ocasión para que los indigenismos aparezcan en los documentos de este periodo. En este caso, las voces de Tierra Firme no podrán siempre desplazar a las taínas, a pesar de que el nahua oponía sus propios términos, pero rara vez subsistieron (Lope Blanch 1990).

Esta presentación de la incorporación de los indigenismos en el español atlántico de este periodo queda incompleta sino se tienen cuenta lo que sucede en las Islas Canarias. Este pequeño archipiélago de siete islas (El Hierro, Fuerteventura, Gran Canaria, La Gomera, La Palma, Lanzarote, y Tenerife), está muy cerca de África, y es camino natural hacia América gracias a las condiciones de vientos alisios y de las mareas atlánticas.

Colón utiliza Canarias como puerto de avituallamiento en su primer viaje al Nuevo Mundo, y al describir a los indígenas de América toma como modelo a los canarios o guanches:

Muy bien hechos, de muy fermosos cuerpos y muy buenas caras. Los cabellos gruessos cuasi como sedas de cola de caballo y cortos. Los cabellos traen por encima de las cejas, salvo unos pocos detrás que traen largos, que jamás cortan. D’ellos se pintan de prieto, y ellos son de la color de los canarios, y ni negros ni blancos [...]. (Alvar 1984: 78; énfasis ?)

[al tratar de explicar cómo son las mujeres que habitan en esa isla] son de muy buen acatamiento, ni muy negras, salvo menos que canarias. (Alvar 1984: 78)

Esta referencia esconde una intención política y social en un contexto de rivalidad luso-castellana, ya que con los acuerdos Alcaçovas-Toledo (1479-1480) se pacta que Canarias sea territorio castellano, y el Almirante deseaba dejar de manifiesto que se descubre América de manera legal según los acuerdos con los portugueses.

La llegada de los españoles a Canarias fue el siglo XV, pero se retoma la conquista entre 1478 y 1496 coincidiendo en algunos años con la empresa americana. Las primeras islas canarias colonizadas son Lanzarote, Fuerteventura y Hierro (1402-1405), seguidas de Gran Canaria (1478-1492) y Tenerife (1494-1496). Se comprende así que mientras en la colonización de las Canarias a principios del XV se improvisan los medios de llevarla a cabo, en las posteriores, se aprovecha la experiencia adquirida por los castellanos y portugueses en el atlántico. 
Desde el punto de vista lingüístico y social en Canarias, el castellano meridional o norma sevillana fue el modelo de prestigio a pesar de la heterogeneidad de los repobladores. Aunque conjeturamos una situación de bilingüismo (español e indígena) y en algunas zonas (español y portugués), o hablantes que dominaran las tres lenguas (español, portugués e indígena), es de suponer que dado el gran número de españoles y como territorio de la Corona de Castilla

[en] los años inmediatos a la conquista estaríamos, pues, ante dos tipos de transferencias lingüísticas: ante una sustitución del múltiple sustrato aborigen (abandono de la modalidad lingüística que fue suplantada como lengua materna por todos los hablantes) y ante los procesos de préstamo que surgieron de la convivencia lingüística del portugués y el castellano. Esto ha hecho que hayan sido estas lenguas las que mayor número de elementos aportaron a la variedad canaria, condicionada también por otros factores como la adaptación a una realidad sociocultural distinta y la barrera geográfica que el carácter isleño impone a cualquier lengua. (Corbella Díaz 1998: 109)

Los documentos oficiales (notariales y administrativos) de Canarias proporcionan datos de la intensa actividad comercial castellana y lusa en el Archipiélago. En los protocolos del escribano público Hernán Guerra (1508-1510) en La Laguna (Tenerife) figuran 67 vecinos portugueses junto a un número similar de españoles (sin olvidar a los mercantes italianos) que realizan múltiples acciones comerciales como vecinos de las primeras ciudades en Canarias (Pérez Vidal 1991: 78).

En Gran Canaria, el cronista Fray Abreu y Galindo (1590) nos explica la relación entre la caña de azúcar y los lusitanos. Se establecieron las primeras plantaciones que el gobernador Vera había hecho venir de la isla de Madeira 'isla de azúcar', junto con maestros especialistas cañaveros y jornaleros portugueses para que aclimataran e hicieran prosperar dicho cultivo. Esta es la razón para que los portugueses recibieran las mejores tierras (30 fanegas de regadío, frente a las 12 habituales).

Años más tarde, el ingeniero Leonardo Torriani escribe en la Descripción de las Islas Canarias (1594) para informar al rey lo siguiente:

[La isla de Tenerife] tiene mucho comercio, porque está más poblada que Canaria, y dos veces más que La Palma. La mayor parte de la gente son portugueses los cuales, como superan a las demás naciones de España en la industria de la agricultura, han conseguido que esta isla fuese la de mayor feracidad y riqueza. Y en la isla de La Palma, las casas son blancas a la manera portuguesa, estrechas por dentro, y en general sin pozos ni patios; sin embargo, son más altas y más alegres que las de las demás islas. Esta ciudad está poblada por portugueses, castellanos, flamencos, genoveses (citado en Cioranescu 1999: 22; énfasis ???)

Lo mismo sucede en los documentos parroquiales escritos en portugués en el norte de Tenerife (Buenavista y de Guía de Isora) y en La Palma (Garafía) hasta el siglo XVII (Pérez Vidal 1991: 95).

Los lusitanos eran especialistas en el medio geográfico atlántico, la relación con los autóctonos, y el modo de obtener rendimiento económico a Canarias. Su 
gran experiencia en el Atlántico macaronésico fue antes de que los castellanos se interesaran por Canarias entre 1478 y 1496: colonización de Madeira (1425), Azores (1427), las exploraciones hacia Guinea que dan lugar a la ocupación de Cabo Verde (entre 1446 y 1457). Los que llegan en nombre de Castilla valoran este conocimiento, y según los primeros cronistas llegan a pedir ayuda a los portugueses a la hora de conquistar algunas islas:

Viendo él que, al unirse los canarios entre ellos, cada día se hacían más difíciles de vencer, procuró desunirlos, para que, asaltándolos un día aquí y otro día allá, pudiese conseguir la victoria a poco a poco y vías fácilmente de este modo. Para ello, ordenó a Diego de Silva, hidalgo portugués que había llevado consigo a esta guerra, que con doscientos soldados escogidos fuese a asaltar la villa de Gáldar [Gran Canaria]. (Morales Padrón 1993: 56)

Se solicita que se lleven desde Madeira y del occidente peninsular especies vegetales que ayuden a dinamizar la economía canaria, según la crónica lacunense:

el Gouernador Pedro de Vera imbió a España y a la isla de la Madera por frutales, y cañas de asúcares, legumbres, y todo género de ganado y de cassa, y se plantaron por toda la isla muchíssimos cañaberales, que luego comensaron a dar infinito asúcar muy bueno, de forma que la isla en breue tiempo se ennoblesió, y auía en ella mucha cauallería. (Morales Padrón 1993: 226)

La caña de azúcar llega a Canarias por mandato de los españoles quienes solicitan la presencia de los portugueses. Andrés Bernáldez llega a anotar en sus Memorias del reinado de los Reyes Católicos (1500) que los antiguos habitantes: 'No tenían viñas, ni cañas de azúcar, ni avía en la isla la riqueza e fertilidad que agora ay, salvo figueras mucha' (véase Corrales Zumbado y Corbella Díaz 2008: 300).

La importancia del azúcar era tan evidente que durante los primeros decenios del siglo XV, el comercio exterior de Canarias se vio entorpecido por la ausencia de moneda, y el azúcar se convierte en medio de pago. Tan sólo en la isla de Tenerife, el 60 por ciento de los pagos se tuvieron que hacer en azúcar, entre 1508 y 1510 (Aznar Vallejo 2009: 89).

De esta forma, un gran número de profesionales lusos de diferentes oficios se acomodan en el archipiélago. Se trata de una inmigración familiar, que procedía de Guimaräes, Braga y Ponte de Lima, Entre Miño y Douro; De Guarda, Aldea do Ponte y Villamayor, que se corresponde con la frontera de Salamanca; Vallezin, Argamil, Manteigas, en las faldas de la Sierra da Estrella; aldeas del interior como Midoes, San Román, Contengan, Canes, Borosa, Acasiño. Los lusos eran un grupo humano familiarizado con la agricultura, la vid y los cereales, así como con la ganadería. Forman núcleos poblacionales siguiendo el sistema portugués de las feligresías o pagos, con pocos habitantes a lo largo de un camino que los comunica con otra vecindad y que en Tenerife y en La Palma constituyen los caminos reales.

Los lusitanos mantenían contactos continuos con África, impulsados por la búsqueda de las especias y el oro. Sin embargo, los portugueses no estaban solos en esta carrera. Después de la expansión de los reinos cristianos y de la ocupa- 
ción de los territorios musulmanes de la cuenca del Guadalquivir (siglo XIII), los castellanos serán competidores de los lusos y catalanes en el tráfico marítimo del estrecho de Gibraltar.

Los españoles de Canarias participan como los portugueses en el comercio de esclavos africanos a través de las capturas o cabalgadas. Las cabalgadas reportaron mucho dinero a los ibéricos. De hecho, los Reyes Católicos para premiar al andaluz Alonso Fernández de Lugo por sus grandes servicios a la Corona se le concedió la conquista de la isla de la Palma y 'la mitad de los quintos que a nos pertenescen e nos avemos de aver de quales quien tomas o cabalgadas, que vos e las gentes que llevavedes o vuestros navíos e fustas [...] tomaren [...] de qualesquier lugares de Berbería [...]' (Aznar Vallejo 2009: 99).

A pesar del gran número de datos sobre la representación numérica de los portugueses en Canarias, no se trata de un condominio entre los dos reinos ibéricos. La presencia lusa fue requerida por los hispánicos, desde un punto de vista práctico y comercial. Y a mediados del siglo XVI, residen en Canarias como vecinos. Éstos llegan a tomar cargos públicos locales (nunca en órganos de decisión como los cabildos), y reciben tierras y los derechos de utilizar el agua (esencial en Canarias) como un privilegio necesario en el desarrollo de los muchos oficios que ocupan en el archipiélago (a pesar de las quejas de los castellanos). Estos datos son más significativos si los comparamos con los que recibieron los indígenas canarios, a los que no se siempre repartieron ni tierra, ni se les dio la oportunidad de acceder al agua, ni a cargos públicos (Aznar Vallejo 2009: 231).

Pero también, los lusos vivirán como estantes, camino a América: 'Procédase con todo rigor contra los extranjeros que fueran en los navíos que van de Canarias a la isla Española, contra los portugueses que van con sus navíos a hacer ventas fingidas' (1562, Archivo General de Indias, Libro Española G. folio 260).

Solicitud de redacción de un documento al Juez Oficial de la isla de La Palma para que los navíos portugueses o de allí vinieren a las islas de Canarias no yendo despachados por los Oficiales de Sevilla o de Cádiz para las Indias no los dejen pasar (1566, Archivo General de Indias Libro General último, folio 275).

Por su parte, los indígenas canarios viven en las zonas rurales apartadas de las ciudades y su principal actividad es el cuidado del ganado. Los datos de los cronistas nos indican las diferencias de este pueblo que vestían con pieles o iban desnudos con los europeos:

[L]as pieles adobaban a modo de gamuzas de que hacían su vestido. El primero i más pulido era una tuniceta con medias mangas cerradas hasta la sangradera i por uajo de la cintura, era en hombres i mujeres principales. En las mujeres ponían ensima como naguas de faldellón otro atado a la sintura i después otra ropa que las cubría todas como casacón o sobretodo. En los hombres eran tres, el primero de el modo que diximos a modo a la rodilla el último de pieles más gruesas i largo hasta los pies. Los pleueios andaban descalços de pie i pierna i trasquilados barba i cauello i con un zamarrón de pieles sin costura por los hombros, los brafos de fuera i algunas veces con media manguilla i en lo interior tenían por la cintura cubierta sus partes. (Morales Padrón 1993: 370) 
En Canarias cada una de las siete islas está poblada por autóctonos con lengua propia de distintas procedencias, con un clara influencia bereber, pero sin olvidar que en las Islas Canarias es posible encontrar voces indígenas de origen diverso.

Esta diversidad lingüística del léxico indígena no está plenamente representada en los textos españoles de los siglos XV, XVI y XVII. En dichos documentos aparece un léxico fruto de los contactos de los autóctonos con viajeros, nuevos pobladores, estantes, comerciantes, etc., entre las islas, o de los intérpretes árabes que acompañaban a los europeos, etc. (Zyhlarz 1950: 414).

De hecho, los europeos perciben diferencias entre los habitantes, de cada isla, que eran conocidos por gentilicios distintos: auritas (La Palma), bimbaches (El Hierro), canarii o canarios (Gran Canaria), gomeros (La Gomera), guanches (Tenerife), y mahoreros (Fuerteventura y Lanzarote). Por su parte, la bibliografía hispánica, al no contar con datos precisos de la etimología (aurita, mahorera, etc.), ha simplificado a la hora de nominar los préstamos léxicos al español como voces guanches (nombre derivado de los habitantes de Tenerife).

Según el sacerdote andaluz Andrés Bernáldez (1450-1513) en sus Memorias del Reinado de los Reyes Católicos escribe sobre 1500: 'Estas siete islas tienen siete lenguajes, cada una el suyo, que no se entendían ni parecían unos a otros; los cuales agora los de la nación de ellos retienen entre ellos’ (véase Corbella Díaz 1998: 100).

Pero todas estas lenguas se perdieron por un proceso de aculturación muy rápido, que impidió que los indígenas tuvieran una huella cultural en las primeras ciudades canarias. Como sucedió en América en el siglo XVI, los autóctonos canarios se vez diezmados a causa de la guerra con los conquistadores, la llegada de nuevas enfermedades europeas, y la esclavitud:

esta verdad, que Guanarteme hizo reseña quando llegaron los españoles de nuebe mil canarios de pelea [...]; otros dicen que fueron dies mil i más. Llanamente más de dos tercios de ellos eran ia muertos quando la conquista, que fuera imposible ganarlos. (Abreu Galindo 1977: 148)

Solíanse juntar, antes que los Católicos Reyes la conquistaran, cerca de catorce mil hombres de pelea; y Nuestro Señor fue servido y permitió hubiese enfermedad en la isla, que llevó de tres partes las dos de gente. (Abreu Galindo 1977: 148-49)

Antón Viejo, vezino de la ysla de La Gomera, testigo presentado sobre la dicha razón, dixo que sabe que quando el governador Francisco Maldonado vino a Canaria nuevamente partieron de La Gomera quatro o cinco navíos de armada de conserva para la ysla de La Palma e que a la sazón e tiempo hera de ynfieles e que este testigo era capitán de vno de los dichos navíos e Sayavedra, vesino de Grand Canaria, defunto que Dios aya, era capitán de la caravela de Gonçalo Ferrandes, portogués, defunto que Dios aya, e que saltaron en la dicha ysla de La Palma e tomaron ochenta e dos ánimas de esclavos, poco más o menos, de las quales tomaron las çinquenta e dos, poco más o menos, en Los Mocanes. (Abreu Galindo 1977: 188)

Los términos indígenas que aparecen en los documentos canarios cumplen un proceso de selección acorde a las necesidades de las primeras sociedades isleñas, pero en competencia con voces españolas y portuguesas (occidentalismos léxicos) a la hora de nombrar la novedad canaria. 


\section{Material y método}

Para alcanzar los objetivos que nos proponemos en el presente trabajo es indispensable contar con un amplio repertorio léxico. Los textos son la única fuente de la lengua hablada en las islas en aquellos primeros momentos de la conquista. El grado de conocimiento que tenemos en la actualidad sobre esta materia es, sin duda, limitado.

Principalmente, los textos que sirven de fundamentación forman parte de las recopilaciones publicadas en los diccionarios históricos y etimológicos del español de Canarias: Diccionario Histórico del Español de Canarias (DHEC) (Corrales Zumbado y Corbella Díaz 2001); y Diccionario Histórico-Etimológico del Habla Canaria (DHEHC) (Morera Pérez 2001). También, se ha tenido en cuenta otros estudios históricos y filológicos como recopilaciones de documentos administrativos (más cercanos a la lengua hablada que las crónicas), repartimientos de terrenos, etc.

El material es sólo una pequeña muestra del extenso y diverso vocabulario que debieron manejar los hablantes de español en las Islas durante el primer momento de la colonización. Además es una fracción no homogénea de este léxico, es decir, no están igualmente representados todos los repertorios que debieron utilizarse. Por ejemplo, a través del espigueo documental contamos con una extensa nómina de términos relacionados con la industria del azúcar, con su comercio y cultivo que posibilita el análisis de un corpus propio de los lusitanos. En palabras de Corrales Zumbado y Corbella Díaz:

Los documentos de los siglos XV, XVI y XVII nos permite hoy conocer con bastante detalle cómo fue traspasándose de la lengua portuguesa a la española un amplio caudal de voces, que junto con las innovaciones propias producidas en las Islas dieron origen a una terminología nueva en español, buena parte de la cual sobrevivirá hasta hoy en América, e incluso continuarán asimilándose allí aquellos términos que no lo habían sido por completo en el uso isleño, con el desplazamiento de la industria azucarera a aquel continente, mientras que en Canarias desaparecerá por completo. Tenemos, pues, en el plano lingüístico, un ejemplo bien dibujado de contacto de lenguas, en un espacio y en un tiempo concretos, así como en un ámbito específico, por lo que su análisis nos dará las claves del comportamiento seguido por dos lenguas hermanas en íntima comunicación, entre las cuales hay claras similitudes e identidades, y la transmisión léxica de una a otra no debe suponer casi nunca grave dificultad o cambio extremo. (2008: 432)

También son numerosos los términos relacionados con la construcción, la importación o exportación de textiles, utensilios del hogar, etc., mientras que el léxico ganadero, pesquero o relacionado con la naturaleza no aparece en los textos. De esta manera, no hay constancia del sector primario propio de los indígenas y portugueses.

El número de voces recopiladas que formen un corpus en el que encontremos voces romances e indígenas no es muy numeroso, por lo tanto debe ser más cualitativo que cuantitativo, intentando extraer los diferentes motivos y procesos que llevaron a la elección de un término frente a otro. Tampoco se recurre a todos las voces registradas hasta 1600 para la consecución de este estudio, ya que 
no en todos los casos pudo darse esta pugna entre voces de distintos orígenes. Pensemos por ejemplo, en vocablos de la industria de la caña de azúcar introducida por los europeos que no debieron tener un sinónimo en el habla aborigen. En esta misma situación estarían los términos que hacen referencia a objetos que no existiesen en las Islas antes de la llegada de los occidentales.

La forma de analizar estos procesos de selección del léxico debe ser individual para cada vocablo. Debe estudiarse cada caso por separado, sin una generalización previa, intentando saber qué ocurrió en cada caso particular, es decir, en cada grupo de sinónimos, para poder obtener conclusiones que sean posteriormente generalizables.

Es importante también el conocimiento de los referentes: objetos, plantas, animales, que quieren designarse con los términos estudiados, para poder saber si los vocablos en pugna son sinónimos o poseen algún matiz diferente que evite esta competencia. Por ejemplo, es viable pensar que tagasaste y escobón son términos sinónimos para nombrar al arbusto endémico Chamaecytisus proliferus.

En este caso podría pensarse en una posible competencia entre ambos términos, cosa inexistente ya que mientras el escobón es el nombre más usual de varias variedades de esta especie, en Canarias se conoce como tagasaste únicamente a una subespecie de Chamaecytisus proliferus, visiblemente distinta a las demás, muy empleada en ganadería y extendida por todas las islas con este fin (Arco Aguilar 1993: 54).

Se requiere por tanto un repertorio que cumpla unas condiciones adecuadas para este tipo de análisis. Las características o parámetros que debiera cumplir el inventario de voces recopiladas son las siguientes:

- Que exista un buen número de términos recogidos en el intervalo historio objeto de análisis (1496-1600)

- Que la materia nombrada existiese en las Islas antes de la llegada de los europeos y que su importancia fuese suficiente entre los aborígenes como para creer que debieron darle una designación en su lengua. Además, que dicha entidad no hubiera desaparecido al iniciarse la conquista, como ocurrió con algunos los referentes culturales, religiosos o sociales de los primitivos pobladores de Canarias.

- Que el conocimiento sobre dicho referente sea suficiente como para dilucidar si existió o no una verdadera competencia entre términos para denominar a dicha entidad o referente.

De todos los repertorios léxicos que conocemos en el español hablado en Canarias en dicho tramo temporal: vocabulario azucarero, religioso, relacionado con la vid, militar, etc., el que mejor cumple los parámetros (abundancia de ejemplos, forme parte de Canarias antes de la llegada de las lenguas romances, perviva después del proceso de colonización) como inventario de voces según los objetivos de la investigación son los fitónimos.

El hecho de que esta investigación se realice con los nombres de las plantas, no quiere decir que la metodología propuesta sea exclusiva de dicha área léxica. 


\section{Resultados}

El inventario de voces que proviene de estudios etimológicos (DHEC; Corrales Zumbado y Corbella Díaz 2001) y DHEHC (Morera Pérez 2001) cuenta con 120 fitónimos hasta 1600. Entre dichos vocablos se reconocen 81 especies o grupos de vegetales claramente definidos. De éstos, 66 fueron conocidos por los aborígenes canarios, según consta en el registro arqueológico, en los textos descriptivos o en tratados etnográficos (Arco Aguilar 1993: 43). Este conocimiento nos permite interpretar que los primeros habitantes de las islas debían tener nombres concretos para todas estas plantas. Sería difícil pensar que un pueblo tan ligado al medio y del que obtenía alimento, combustible, comida para el ganado, medicinas para curar enfermedades, etc., no tuviese un término adecuado para nombrar la naturaleza en la que vivían (cardones, sabinas, madroños, etc.), lo que sucede es que no fue registrado en ningún texto.

Con estas premisas, se elabora la Tabla 1 en la que pueden verse las 66 entradas que han sido útiles para el trabajo. Cada vocablo corresponde a una especie o grupo de especies relacionadas, y a cada una de ellas se relacionan varios fitónimos, unos registrados, y otros sin registrar pero que como se ha apuntado anteriormente, existieron con toda seguridad.

Además de estas 66 referentes, se han inventariados otros fitónimos referidos a 12 especies pero que fueron introducidas por los europeos en las islas, por lo que los aborígenes canarios no las podían conocer. Son entre otras: durazno, pera, bimbre, caña, etc. Finalmente, se han desechado varios fitónimos: mocán 'Visnea mocanera' y tamara 'fruto de la palmera canaria' por la dudas sobre su origen. La cuantificación de este análisis nos muestra unos datos que quedan referidos en la Tabla 2 . En ella se desglosan todos los términos examinados según procedan de una lengua u otra y según prevalezca finalmente un origen $u$ otro. Se ofrecen los datos numéricos y los porcentajes de cada grupo.

El inventario de 66 entidades (especies), de las que 53 tienen se designan preferentemente a través de un término castellano (el grupo a) de referentes) representan un 80.30 por ciento del 66 especies referentes). Pero también es posible encontrar 33 especies de plantas en los que las designaciones pueden ser castellana, portuguesa o indígena guanche (el 50 por ciento del total de referentes), ya que existe al menos un término en cada lengua que designa a la misma especie o grupo de especies.

El grupo de referentes b) tan sólo conforman un poco más del 12 por ciento, y las voces de origen castellano no aparecen en los textos.

Tanto en a) como en b) es posible analizar la pugna entre las lenguas romances e indígenas. En a) contabilizamos 16 entidades en los que las designaciones castellanas y guanches se presentan en los textos; cuatro referentes, que no está claro el término autóctono. Por su parte en b), ocho referentes palabras de origen aborigen reciban designaciones portuguesas y aborígenes.

Y por último, en los ejemplos de c) localizamos cinco especies o referentes en los que parece que no existió competencia porque el término aborigen guanche se integra en los documentos. 
Tabla 1: Especies o genéricos y sus designaciones encontradas en textos canarios hasta 1600

\begin{tabular}{|c|c|c|c|c|c|}
\hline $\begin{array}{l}\text { Referentes } \\
\text { (especies o } \\
\text { grupos de } \\
\text { especies) }\end{array}$ & Término/s & Español & Portugués & Guanche & $\begin{array}{l}\text { Origen del } \\
\text { vocablo que } \\
\text { aparece en los } \\
\text { textos }\end{array}$ \\
\hline $\begin{array}{l}\text { Adenocarpus } \\
\text { spp. }\end{array}$ & Codeso & $\mathrm{X}$ & 0 & $\mathrm{X}$ & E \\
\hline $\begin{array}{l}\text { Apollonias } \\
\text { barbujana }\end{array}$ & Barbuzano & 0 & $X$ & $\mathrm{X}$ & $\mathrm{P}$ \\
\hline $\begin{array}{l}\text { Arbutus } \\
\text { canariensis }\end{array}$ & Madroño & $\mathrm{X}$ & $\mathrm{X}$ & $\mathrm{X}$ & E \\
\hline $\begin{array}{l}\text { Argyranthemum } \\
\text { spp. }\end{array}$ & Magarza & $\mathrm{X}$ & $\mathrm{X}$ & $\mathrm{X}$ & E \\
\hline $\begin{array}{l}\text { Artemisia } \\
\text { canariensis }\end{array}$ & Incienso/mol & $\mathrm{X}$ & $\mathrm{X}$ & $\mathrm{X}$ & $\mathrm{E} / \mathrm{g}$ \\
\hline $\begin{array}{l}\text { Bistropogon } \\
\text { origanifolium }\end{array}$ & Poleo & $\mathrm{X}$ & 0 & $\mathrm{X}$ & E \\
\hline $\begin{array}{l}\text { Canarina } \\
\text { canariensis }\end{array}$ & Bicácaro & 0 & 0 & $\mathrm{X}$ & G \\
\hline $\begin{array}{l}\text { Carduus spp, } \\
\text { Cynara spp., } \\
\text { etc. }\end{array}$ & Cardo & $\mathrm{X}$ & $\mathrm{X}$ & $\mathrm{X}$ & E \\
\hline $\begin{array}{l}\text { Carlina } \\
\text { salicifolia }\end{array}$ & Alazor & $\mathrm{X}$ & $\mathrm{X}$ & $\mathrm{X}$ & E \\
\hline Ceropegia spp. & Cardoncillo & $\mathrm{X}$ & 0 & $\mathrm{X}$ & E \\
\hline $\begin{array}{l}\text { Chamaecytisus } \\
\text { proliferus }\end{array}$ & Escobón & $X$ & 0 & $\mathrm{X}$ & E \\
\hline $\begin{array}{l}\text { Cistus } \\
\text { monspeliensis }\end{array}$ & Jaguarzo & $\mathrm{X}$ & $\mathrm{X}$ & $\mathrm{X}$ & E \\
\hline $\begin{array}{l}\text { Cistus } \\
\text { symphytifolius }\end{array}$ & $\begin{array}{l}\text { Jarón/ } \\
\text { Amagante }\end{array}$ & $\mathrm{X}$ & $\mathrm{X}$ & $\mathrm{X}$ & E/g \\
\hline $\begin{array}{l}\text { Convolvulus } \\
\text { scoparius }\end{array}$ & Leñanoel & $\mathrm{X}$ & 0 & $\mathrm{X}$ & E \\
\hline Daphne gnidium & Torvisco & $\mathrm{X}$ & 0 & $\mathrm{X}$ & E \\
\hline $\begin{array}{l}\text { Diversas } \\
\text { especies de } \\
\text { compuestas } \\
\text { espinosas }\end{array}$ & Alcaucil & $\mathrm{X}$ & $\mathrm{X}$ & 0 & E \\
\hline Dracaena draco & Drago & $\mathrm{X}$ & $\mathrm{X}$ & $\mathrm{X}$ & E \\
\hline Echium spp. & Taginaste & 0 & 0 & $\mathrm{X}$ & G \\
\hline Erica arbórea & Brezo & $\mathrm{X}$ & $\mathrm{X}$ & $\mathrm{X}$ & E \\
\hline Erica scoparia & Tejo & $\mathrm{X}$ & $\mathrm{X}$ & $\mathrm{X}$ & $\mathrm{E}$ \\
\hline $\begin{array}{l}\text { Euphorbia } \\
\text { canariensis }\end{array}$ & Cardón & $\mathrm{X}$ & 0 & $\mathrm{X}$ & E \\
\hline Euphorbia spp. & Tabaiba & 0 & 0 & $\mathrm{X}$ & G \\
\hline Ficus carica & $\begin{array}{l}\text { Breva, } \\
\text { higuera }\end{array}$ & $\mathrm{X}$ & $X$ & $\mathrm{X}$ & E \\
\hline $\begin{array}{l}\text { Foeniculum } \\
\text { vulgare }\end{array}$ & Matalahúja & $\mathrm{X}$ & $\mathrm{X}$ & 0 & $\mathrm{E}$ \\
\hline $\begin{array}{l}\text { Fruto del } \\
\text { mocán }\end{array}$ & Yoya & 0 & 0 & $\mathrm{X}$ & G \\
\hline
\end{tabular}




\begin{tabular}{|c|c|c|c|c|c|}
\hline $\begin{array}{l}\text { Referentes } \\
\text { (especies o } \\
\text { grupos de } \\
\text { especies) }\end{array}$ & Término/s & Español & Portugués & Guanche & $\begin{array}{l}\text { Origen del } \\
\text { vocablo que } \\
\text { aparece en los } \\
\text { textos }\end{array}$ \\
\hline $\begin{array}{l}\text { Haberdenia } \\
\text { excelsa }\end{array}$ & Aderno & 0 & $\mathrm{X}$ & $\mathrm{X}$ & $\mathrm{P}$ \\
\hline $\begin{array}{l}\text { Hedera } \\
\text { canariensis }\end{array}$ & Yedra & $\mathrm{X}$ & $\mathrm{X}$ & $\mathrm{X}$ & E \\
\hline Hongo & Alhorra & $\mathrm{X}$ & $\mathrm{X}$ & $\mathrm{X}$ & $\mathrm{P}$ \\
\hline $\begin{array}{l}\text { Hyparrhenia } \\
\text { spp. }\end{array}$ & Cerrillo & $\mathrm{X}$ & 0 & $\mathrm{X}$ & E \\
\hline $\begin{array}{l}\text { Hypericum } \\
\text { canariensis }\end{array}$ & Granadillo & $\mathrm{X}$ & 0 & $\mathrm{X}$ & E \\
\hline Mlex canariensis & Acebiño & 0 & $\mathrm{X}$ & $\mathrm{X}$ & $\mathrm{P}$ \\
\hline Juncus spp. & Juncia & $\mathrm{X}$ & $\mathrm{X}$ & $\mathrm{X}$ & $\mathrm{E}$ ? \\
\hline $\begin{array}{l}\text { Juniperus cedrus } \\
\text { Juniperus }\end{array}$ & Cedro & $\mathrm{X}$ & $\mathrm{X}$ & $\mathrm{X}$ & $\mathrm{E}$ \\
\hline $\begin{array}{l}\text { turbinata ssp. } \\
\text { canariensis }\end{array}$ & Sabina & $\mathrm{X}$ & $\mathrm{X}$ & $\mathrm{X}$ & E \\
\hline $\begin{array}{l}\text { Laurus } \\
\text { novocanariensis }\end{array}$ & Laurel/loro & $\mathrm{X}$ & $\mathrm{X}$ & $\mathrm{X}$ & $\mathrm{E} / \mathrm{P}$ \\
\hline Lavandula spp. & $\begin{array}{l}\text { Hierba de } \\
\text { risco }\end{array}$ & $\mathrm{X}$ & 0 & $\mathrm{X}$ & E \\
\hline Lolium spp. & Joyo & $\mathrm{X}$ & 0 & $\mathrm{X}$ & E \\
\hline Morella faya & Haya/faya & $\mathrm{X}$ & $\mathrm{X}$ & $\mathrm{X}$ & $\mathrm{e} / \mathrm{P}$ \\
\hline $\begin{array}{l}\text { Nasturtium } \\
\text { officinalis }\end{array}$ & Berros & $\mathrm{X}$ & $\mathrm{X}$ & 0 & $\mathrm{E}$ \\
\hline $\begin{array}{l}\text { Neochamaelea } \\
\text { pulverulenta }\end{array}$ & $\begin{array}{l}\text { Leña santa/ } \\
\text { orijama }\end{array}$ & $\mathrm{X}$ & 0 & $\mathrm{X}$ & E/g \\
\hline Ocotea foetens & Til, garoé & 0 & $\mathrm{X}$ & $\mathrm{X}$ & $\mathrm{P}$ \\
\hline Olea cerasiformis & Acebuche & $\mathrm{X}$ & $\mathrm{X}$ & $\mathrm{X}$ & $\mathrm{E}$ \\
\hline Persea indica & $\begin{array}{l}\text { Viñátigo/ } \\
\text { carisco }\end{array}$ & 0 & $\mathrm{X}$ & $\mathrm{X}$ & $\mathrm{P} / \mathrm{g}$ \\
\hline $\begin{array}{l}\text { Phoenix } \\
\text { canariensis }\end{array}$ & Palma & $\mathrm{X}$ & $\mathrm{X}$ & $\mathrm{X}$ & $\mathrm{E}$ \\
\hline Picconia excelsa & Palo blanco & $\mathrm{X}$ & $\mathrm{X}$ & $\mathrm{X}$ & $\mathrm{E}$ ? \\
\hline $\begin{array}{l}\text { Pinus } \\
\text { canariensis }\end{array}$ & Pino & $\mathrm{X}$ & $\mathrm{X}$ & $X$ & $\mathrm{E}$ \\
\hline $\begin{array}{l}\text { Pistacia } \\
\text { atlántica }\end{array}$ & Almácigo & $\mathrm{X}$ & 0 & $\mathrm{X}$ & E \\
\hline Pistacia lentiscus & Lentisco & $\mathrm{X}$ & $\mathrm{X}$ & $\mathrm{X}$ & E \\
\hline Pisum sativum & Arveja & $\mathrm{X}$ & $\mathrm{X}$ & $\mathrm{X}$ & E \\
\hline Plocama pendula & Balo, valo & 0 & 0 & $\mathrm{X}$ & G \\
\hline $\begin{array}{l}\text { Rhamnus } \\
\text { glandulosus }\end{array}$ & Sanguino & 0 & $\mathrm{X}$ & $\mathrm{X}$ & $\mathrm{P}$ \\
\hline Roccella spp. & Orchilla & $\mathrm{X}$ & 0 & $\mathrm{X}$ & E \\
\hline Rubus spp. & Zarza & $\mathrm{X}$ & $\mathrm{X}$ & $\mathrm{X}$ & E \\
\hline Salix canariensis & $\begin{array}{l}\text { Sabce, sauce, } \\
\text { sao }\end{array}$ & $\mathrm{X}$ & $\mathrm{X}$ & $\mathrm{X}$ & E \\
\hline Salvia spp. & Salvia, salvias & $\mathrm{X}$ & $\mathrm{X}$ & $\mathrm{X}$ & $\mathrm{E}$ \\
\hline $\begin{array}{l}\text { Sambucus } \\
\text { palmensis }\end{array}$ & Saúco/sabugo & $\mathrm{X}$ & $\mathrm{X}$ & $\mathrm{X}$ & $\mathrm{E} / \mathrm{P}$ \\
\hline $\begin{array}{l}\text { Semele } \\
\text { androgyna }\end{array}$ & Gilbarbera & 0 & $\mathrm{X}$ & $X$ & $\mathrm{P}$ \\
\hline
\end{tabular}




\begin{tabular}{|c|c|c|c|c|c|}
\hline $\begin{array}{l}\text { Referentes } \\
\text { (especies o } \\
\text { grupos de } \\
\text { especies) }\end{array}$ & Término/s & Español & Portugués & Guanche & $\begin{array}{c}\text { Origen del } \\
\text { vocablo que } \\
\text { aparece en los } \\
\text { textos }\end{array}$ \\
\hline $\begin{array}{l}\text { Sideroxilum } \\
\text { marmulano }\end{array}$ & Marmulano & 0 & $\mathrm{X}$ & $\mathrm{X}$ & $\mathrm{P}$ \\
\hline Smilax spp. & Zarzaparrilla & $\mathrm{X}$ & $\mathrm{X}$ & 0 & E \\
\hline Sonchus spp. & Cerraja & $\mathrm{X}$ & 0 & $\mathrm{X}$ & E \\
\hline $\begin{array}{l}\text { Sysimbrium } \\
\text { spp. }\end{array}$ & Taferte & $\mathrm{X}$ & $\mathrm{X}$ & $\mathrm{X}$ & G \\
\hline $\begin{array}{l}\text { Tamarix } \\
\text { canariensis }\end{array}$ & Tarajal & $\mathrm{X}$ & $\mathrm{X}$ & $\mathrm{X}$ & $\mathrm{E}$ \\
\hline $\begin{array}{l}\text { Teline spp., } \\
\text { Spartocytisus } \\
\text { spp. Retama } \\
\text { spp. }\end{array}$ & Retama & $\mathrm{X}$ & $\mathrm{X}$ & $\mathrm{X}$ & E \\
\hline $\begin{array}{l}\text { Triticum } \\
\text { aestivum }\end{array}$ & $\begin{array}{l}\text { Trigo } \\
\text { morisco, } \\
\text { morisquillo }\end{array}$ & $\mathrm{X}$ & 0 & $\mathrm{X}$ & E \\
\hline $\begin{array}{l}\text { Varias especies } \\
\text { de helechos }\end{array}$ & Helechera & $\mathrm{X}$ & $\mathrm{X}$ & $\mathrm{X}$ & E \\
\hline $\begin{array}{l}\text { Withania } \\
\text { aristata }\end{array}$ & Oroval & $\mathrm{X}$ & $\mathrm{X}$ & $\mathrm{X}$ & E \\
\hline
\end{tabular}

$\mathrm{X}=$ se data un término con este significado en la lengua

$0=$ no existió término con este significado en la lengua

$\mathrm{E}=$ término español

$\mathrm{P}=$ vocablo portugués

$\mathrm{G}=$ lexía indígena o guanche

$\mathrm{E} / \mathrm{P}, \mathrm{P} / \mathrm{G}$, etc.: Si se indican dos orígenes en los vocablos que aparecen en los textos, representa que hoy se emplean términos de ambos orígenes.

$\mathrm{E} / \mathrm{g}$, P/g, etc.: La letra minúscula significa que existe un término de este origen pero que es muy minoritario (por ejemplo, se usa sólo en una isla).

E?: Si se añade una interrogante en el origen se expresa que se duda de que sea un término de origen castellano.

En la Fig. 1 se plasma de manera visual cómo se reparten los orígenes entre los fitónimos localizados en los textos de los siglos XV y XVI. De todas las especies analizadas, un total de sesenta y seis, más del 65 por ciento se conocen por su designación en español, mientras que sólo el 13.64 por ciento mantienen su denominación en portugués y en poco más del 9 por ciento permaneció su nombre en el idioma prehispano. Queda patente el equilibrio que adquirieron los diferentes vocabularios español, luso y guanche.

Es posible añadir el parámetro de lenguaje especializado al análisis, para no establecer una relación entre áreas léxicas y origen de los fitónimos. Es decir, sería razonable que un término prevaleciese sobre el resto cuando el vocabulario especializado al que pertenece formase un inventario de voces y que este grupo se transfiera de una lengua a otra en bloque. Por ejemplo, si se sabe que los aborígenes canarios quedaron después de la conquista vinculados con la ganadería, podría pensarse que la mayor parte de las designaciones empleadas en esta 
Tabla 2: Análisis de los términos encontrados según su procedencia y la aparición de los textos de uno u otro origen

\begin{tabular}{|c|c|c|c|c|c|c|c|c|c|c|}
\hline \multirow[b]{2}{*}{$E P G$} & \multirow{2}{*}{$\begin{array}{l}N^{o} \text { de } \\
\text { referentes }\end{array}$} & \multicolumn{4}{|c|}{$\begin{array}{l}\text { Origen de los fitónimos que } \\
\text { aparecen en los textos }\left(n^{\circ}\right)\end{array}$} & \multirow{2}{*}{$\begin{array}{l}\% \text { de } \\
\text { referentes }\end{array}$} & \multicolumn{4}{|c|}{$\begin{array}{l}\text { Origen de los términos que } \\
\text { aparecen en los textos (\%) }\end{array}$} \\
\hline & & $E$ & $P$ & $G$ & Otros & & $E$ & $P$ & $G$ & Otros ${ }^{1}$ \\
\hline a) $X_{--}{ }^{2}$ & 53 & 43 & 1 & 1 & 8 & 80.30 & 81.13 & 1.89 & 1.89 & 15.09 \\
\hline XXX & 33 & 25 & 1 & 1 & 6 & 50.00 & 75.76 & 3.03 & 3.03 & 18.18 \\
\hline XX0 & 4 & 4 & 0 & 0 & 0 & 6.06 & 100 & 0.00 & 0.00 & 0.00 \\
\hline $\mathrm{X} 0 \mathrm{X}$ & 16 & 14 & 0 & 0 & 2 & 24.24 & 87.50 & 0.00 & 0.00 & 12.50 \\
\hline b) $0 X_{-}^{3}$ & 8 & 0 & 8 & 0 & 0 & 12.12 & 0.00 & 100 & 0.00 & 0.00 \\
\hline OXX & 8 & 0 & 8 & 0 & 0 & 12.12 & 0.00 & 100 & 0.00 & 0.00 \\
\hline OX0 & 0 & 0 & 0 & 0 & 0 & 0.00 & 0.00 & 0.00 & 0.00 & 0.00 \\
\hline c) $00 X^{4}$ & 5 & 0 & 0 & 5 & 0 & 7.58 & 0.00 & 0.00 & 100 & 0.00 \\
\hline TOTAL & 66 & 43 & 9 & 6 & 8 & 100 & 65.15 & 13.64 & 9.09 & 12.12 \\
\hline
\end{tabular}

$\mathrm{E}=$ término español

$\mathrm{P}=$ vocablo portugués

$\mathrm{G}$ = lexía indígena o guanche

1 Se incluye vocablos que no queda claro el origen (castellano o portugués) y que conviven a la hora de denominar un referente: de origen discutido están mocán y támara, y con términos de distinto origen sin que domine uno de ellos encontramos sahuco/sabugo, laurel/ loro, etc.

2 Plantas o referentes con un término castellano para nombrarlos, tengan o no a su vez designaciones en portugués o indigenismos guanches.

3 Referentes con designaciones portuguesas, y que pueden o no tener un nombre en guanche.

4 Entidades (especies o grupos de especies) a la que se refiere un indigenismo guanche.

actividad, proceden de esta lengua, o si los leñadores y madereros en Canarias, cuyo principal trabajo era el de producir leña y madera para los ingenios de azúcar, eran primordialmente de habla portuguesa, los fitónimos que designan a árboles o arbustos maderables tendrían preferentemente este origen.

Las especies o grupos de especies analizados se han fraccionado en el uso: maderero, forrajeras y uso alimentario. De este análisis (véase la Tabla 3) se extraen los siguientes datos: de las 43 referentes en los que predominó finalmente un término de origen español, 19 estaban relacionados con árboles o arbustos maderables, 23 eran de especies forrajeras y 10 denominaban a especies comestibles.

De las nueve especies o grupos de especies en los que prevaleció un término de origen portugués para su designación, siete se corresponden a especies maderables, y los otros dos no tenían ninguna utilidad de las enumeradas. Finalmente, los cinco referentes en los que prevaleció un término de origen guanche, sólo dos se corresponden a especies forrajeras, y otras dos se empleaban en la alimentación humana. El protagonismo de las voces españolas en todos los casos es fehaciente, seguido del portugués e indigenismo. 
Fig. 1: Proporción de los orígenes de los fitónimos que quedaron registrados en los textos del s. XV y XVI

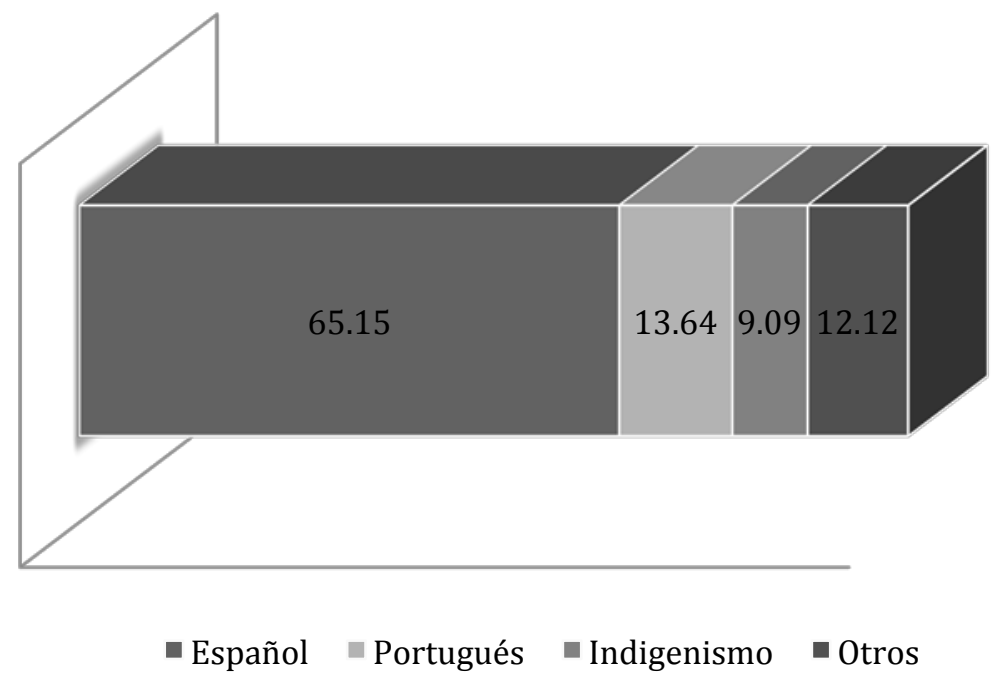

Tabla 3: Relación entre origen de un término y uso de la especie designada

\begin{tabular}{|c|c|c|c|c|c|}
\hline \multirow{2}{*}{$\begin{array}{l}\text { Orígenes de } \\
\text { vocablos según } \\
\text { los textos } \\
\text { hasta } 1600\end{array}$} & \multirow[b]{2}{*}{$\begin{array}{l}n^{o} \text { de } \\
\text { voces }\end{array}$} & \multicolumn{4}{|c|}{ Usos } \\
\hline & & Maderero & Forrajero & Alimenticio & $\begin{array}{l}\text { Otros (que no se pueden } \\
\text { incluir en lo anterior) }\end{array}$ \\
\hline $\mathrm{E}$ & 43 & 19 & 23 & 10 & 4 \\
\hline $\mathrm{P}$ & 9 & 7 & 0 & 0 & 2 \\
\hline G & 6 & 0 & 2 & 2 & 2 \\
\hline
\end{tabular}

\section{Discusión y conclusiones}

Analizados todos los parámetros que pueden interferir en la supervivencia de un fitónimo sobre otro para designar a una especie o grupo de especies, queda claro que la designación española es la que se selecciona con más frecuencia en los textos. El uso que se le dé a la planta parece poco pertinente a la hora de la selección. Sólo en aquellos casos en que no hay un término castellano como posible designación, pueden aparecer voces portuguesas o indígenas guanches.

En el caso de una planta en la que compitan un término de origen portugués con la designación guanche, la selección del término luso en un 100 por ciento. Salvo algunos ejemplos en el indigenismo guanche convive con el portuguesismos: viñátigo/carisco, o a los castellanismos: incienso/mol, leña santa/orijama.

Según nuestros resultados, los indigenismos autóctonos sólo aparecen en los textos si en el castellano ni en el portugués existen posibles términos para designar a una especie o grupo de ellas. Si tenemos en cuenta que la naturaleza canaria es atlántica y macaronésica coincidente con otras áreas portuguesas, se 
comprende los pocos fitónimos guanches que existen en las hablas canarias.

Esto demuestra que es la procedencia del término la que condiciona su supervivencia, y en la escala de competitividad, las voces de origen castellano dominan sobre portugueses y guanches, y los portugueses dominan sobre los aborígenes canarios. Es interesante la constatación de que en este primer estado de formación del vocabulario del español de Canarias apenas hay creación de términos. Sólo cardoncillo y granadillo son palabras de nueva creación, sin relación con ninguna del ámbito peninsular. El resto de las 66 referentes o especies son designados por términos existentes en el castellano peninsular, en el portugués o entre los primitivos pobladores de Canarias.

¿Por qué seleccionan los textos el portuguesismo antes que el indigenismo guanche? Quizá, por la cercanía de las lenguas romances (castellano o portugués), o como sucedió en América porque los textos se redactaron en un contexto urbano, en el que la población de origen lusa (sinónimo de prestigio) estuviese mucho mejor representada que la aborigen (relegada a las zonas rurales alejadas de las urbes). El prestigio de los europeos también aparece en América, según lo que escribió Fernández de Oviedo al intentar incorporar en su crónica de 1535 los indigenismos:

Si algunos vocablos extraños e bárbaros aquí se hallaren, la causa es la novedad de que se tracta; y no se pongan á la cuenta de mi romançe, que en Madrid nasçí y en la casa real me crié y con gente noble he conversado, é algo he leído, para que se sospeche que avré entendido mi lengua castellana, la qual de las vulgares, se tiene por mayor de todas; y lo que oviere en este volumen que con ella no consuene, serán nombres ó palabras por mi voluntad puestos para dar á entender las cosas que por ellos quieren los indios significar. (Enguita Utrilla 1980: 220)

En cuanto a la posible relación entre origen de una designación y el uso en las sociedad canaria hasta 1600 , no se ha encontrado una relación significativa. Parece que la posible hipótesis de vincular la procedencia de los términos de un determinado vocabulario (léxico azucarero, ganadero, etc.) con la procedencia de los grupos humanos que realizan esa actividad, no se verifica con los datos de este estudio.

La actitud ante los préstamos de los que escriben los diferentes textos en lengua española en este periodo parece ser más compleja que la simple aceptación de nuevas voces. La clave de la incorporación de un préstamo en los textos debe entenderse en la incapacidad designativa del vocabulario patrimonial del español como primera elección en los documentos, y la convivencia de españoles y lusos en las ciudades en las que se escriben los documentos.

Queda demostrado que sí existe competencia entre las voces que designan un mismo objeto, y que esta pugna se rige por las reglas del prestigio y la aceptación social que solía estar en el término de procedencia hispánica. 
Obras citadas

Abreu Galindo, Juan de, 1977 [1632]. Historia de la conquista de las siete islas de Gran Canaria (Santa Cruz de Tenerife: Goya).

Alvar, Manuel, 1984. Diario del Descubrimiento de Cristóbal Colón (Las Palmas de Gran Canaria: Cabildo Insular de Gran Canaria).

—, 1990. 'Americanismos en la Historia de Bernal Díaz del Castillo', RFE, anejo LXXXIX.

-, 1996. Manual de Dialectología Hispánica. El español de España (Barcelona: Ariel).

Andión Herrero, María Antonieta, 2005. 'Acerca del léxico antillano y circuncaribe' en la Historia de las Indias de Fray Bartolomé de las Casas', en Filología y Lingüística. 126 estudios ofrecidos a Antonio Quilis. Vol. II (Madrid: CSIC-UNED-Universidad de Valladolid).

Arco Aguilar, Carmen, 1993. Recursos vegetales de la prehistoria de Canarias (Santa Cruz de Tenerife: Cabildo Insular de Tenerife).

Aznar Vallejo, Eduardo, 2009. La integración de las Islas Canarias en la Corona de Castilla (1478-1526) (Las Palmas de Gran Canaria: Cabildo Insular de Gran Canaria).

Bravo García y Cáceres, Lorenzo, 2011. La incorporación del indigenismo léxico en los contextos comunicativos canario y americano: (1492-1550) (Bern: Peter Lang).

Cioranescu, Alejandro, 1999 [1594]. Leonardo Torriani, Descripción e historia del reino de las Islas Canarias, antes Afortunadas, con el parecer de su fortificaciones (Santa Cruz de Tenerife: Cabildo de Tenerife).

Corbella Díaz, Dolores, 1998. 'Contacto de lenguas e interferencias lingüísticas: el caso del español de Canarias’, en Angus Ward (coord.) Actas del XII Congreso de la Asociación Internacional de Hispanistas, I (Las Palmas de Gran Canaria: Cabildo Insular de Gran Canaria), pp. 106-116.

Corrales Zumbado, Cristobal, y Dolores Corbella Díaz, 2001. Diccionario Histórico del Español de Canarias (DHECan). La Laguna de Tenerife: Instituto de Estudios Canarios.

-, 2008. 'Contribución a la historia de la terminología azucarera canaria'. Anuario de estudios atlánticos, pp. 335-59 (Las Palmas de Gran Canaria: Cabildo Insular de Gran Canaria).

Enguita Utrilla, José María, 1980. 'Fernández de Oviedo ante el léxico indígena', BFUCh, XXXI: 203-210.

Lope Blanch, José María, 1990. ‘Antillanismos en la Nueva España’, en Investigaciones sobre Dialectología mexicana, 2a ed. (México: UNAM), pp. 161-69.

Morales Padrón, Francisco, 1993. Canarias: Crónicas de su Conquista. 2a ed. (Las Palmas de Gran Canaria: Ayuntamiento de Las Palmas-Museo Canario).

Morera Pérez, Marcial, 2001. Diccionario Histórico-Etimológico del Habla Canaria (DHEHC) (Santa Cruz de Tenerife: Viceconsejería de Cultura y Deporte).

Pérez Vidal, José, 1991. Los portugueses en Canarias (Las Palmas de Gran Canaria: Cabildo Insular de Gran Canaria).

Zamora Munné, J. C., 2002. 'Indigenismos en la lengua de los conquistadores', Hesperia. Anuario de Filología Hispánica, V: 195-209.

Zyhlarz, Ernst, 1950. 'Das Kanarische Berberisch in seinem sprachgeschichtlichen Milieu', Zeitschrift der Deutschen Morgenländischen Gesellschaft, 100.2: 403-460. 
